\title{
The Study of Influence of Internet Culture on Ideological Education of College Students
}

\author{
Heming Wu \\ Shijiazhuang Vocational Technology Institute, Shijiazhuang, China \\ ae983511007@QQ.COM
}

Keywords: Network Culture; College Students; Ideological and Political Education

\begin{abstract}
The network culture spread at unprecedented speed, it has created a good opportunity for Undergraduates' ideological and political education. But it has also brought some serious challenges for Undergraduates' ideological and political education. Therefore, how to seize the opportunity, meet the challenge, to strengthen and improve Undergraduates' ideological and political education under the network culture is an important issue to be settled urgently.
\end{abstract}

\section{Introduction}

The 21st century is an information and network era, the emergence of the Internet to people's production and life has brought many changes. With the extensive application of information technology and the rapid development of computers, the university is an important position of responsibility in the dissemination of knowledge and information at the forefront of Chinese society, "network" of development. Network as a new technological means necessarily have the double-sided nature of new things, this "double-edged sword" effect as follows: on the one hand, and efficient, information sharing network and its ideological and political education for college students provides a convenient, make scientific information and sources of information gradually expanded, educational technology and teaching methods can be continually improved and updated, to a certain extent, also greatly expanded the space of ideological and political education. On the other hand, open and pluralistic network Information, good and bad ideas, even ideological penetration of Western capitalism unhealthy factors, but also to respect values, political attitudes, personality psychology of college students have brought some negative impact. How active to deal with the impact and challenges of network culture this "double-edged sword" will bring? How to effectively take advantage of the network of ideological and political education, ideological and political Students actively explore new ways and methods of education, and then seize the opportunity to promote the innovation of ideological and political education of college students, which is placed in front of the ideological and political workers and even the whole society of great urgency task.

\section{The Overview of Network Culture}

Advances in technology is not just the production of tools and production changes, a certain sense, it also contains a very rich cultural identity. That is, when a technology has been widely used in the community, when, as the technology itself that it has a cultural function, affecting people's way of thinking and behavior in its marketing activities in the process, so that will be derived from a new cultural forms. Undoubtedly, the use of network technology, too, it is in the process of dissemination and application, is bound to influence and change people's thinking and values, changing the traditional culture of communication in the past, for which also contributed to a new cultural form Production and development of Internet culture. It can be seen that the generation of network culture is accompanied by widespread application and development of network technology developed, it is the objective result of the inevitable trend of modern network science and technology with the world's cultural integration and progress and development.

Internet culture has been an important issue of concern domestic scholars. With the popularization and development of the Internet in recent years, scholars have studied the network culture further, on 
the theme of web culture, eds., Research papers, dissertations, newspapers and books, also gradually increased. Scholars have elaborated different aspects of network culture and research, some in philosophy, psychology and media communication analysis and research as perspective, and some computer networks based on Internet culture generalize. Overall, most studies have focused on the meaning and characteristics of network culture, positive and negative influence of Internet culture; aspects of network culture and traditional culture and the relationship between national culture; cultural paradigm and value network.

\section{The Characteristics of Internet Culture}

Openness of the Internet has brought a culture of sharing information. Network to establish a global network of mutual exchange of common language, which shortened the distance of different races, different classes of people around the world between reality eliminates the geographical boundaries, forming a network of multicultural coexistence "global village". This makes the people around the world to share cultural information through the network, this new media.

Open source network culture information network brings the diversity of cultural content, but also to create the conditions for the multicultural inclusion. The Internet is a vast ocean of information, rich and diverse cultures of the world where intertwined, colliding with each other, including different ethnic and regional economic, political, scientific, educational, religious and other cultural resources, co-located on the same Internet, forming a multi- cultural coexistence and common prosperity, a total exclusion of the situation, together constitute the world's cultural treasure.

Internet culture is a kind of computer technology and communication technology-based culture, generation and development of computer network of cultural heritage provides a new space and the carrier is, making the network culture has to break the boundaries of time and space, beyond the national, regional, race, culture and even language restrictions feature, truly from the "limited" culture to "infinity" culture forward.

Internet culture is a typical type of cultural interaction, interactive network culture in the dissemination process demonstrated by the most important features. Network culture propagation so networks of people-many ways to communicate, people can post in the forum (BBS) on the comments in the blog to express feelings, communicate with friends on QQ and MSN, talk, you can also publish by E-mail announcements and information to achieve paperless office, and interact through these open spaces, the realization of a one, more than one pair, multiple kinds of multiple communication and interaction.

\section{The Positive Effect of Network Culture on College Students' Ideological and Political Education}

All along, the effect of ideological and political education is not satisfactory, the contemporary college students to talk, listen to reports and other pure persuasion and education style education model is not very interested in, but also very tired, and even some college students have tired of psychology. Internet culture is based on text, images, sounds, pictures, etc. as the carrier of the multiple manifestations of the emerging culture, its rich multi-sensory expression stimulated university students and change the past in order to listen to the main single education, ideological and political education to combine multiple sensory stimulation visual education model. Network Culture rich manifestation illustrations, audio and video combined with the like transfer of culture and a more vivid image, which greatly increase the appeal of ideological and political education to attract more college students to receive education initiative.

Network cultural background, ideological and political education body active thinking, complex state of mind, they advocate the development of personality, with different levels of social things, inner needs and personal insights. Internet culture of equality make education and educated in the culture in the same position in front of the network, eliminating the race, family status, cultural background and other restrictions, so that the main ideological and political education to improve the 
confidence of both parties object. Educators can QQ, Email, MSN, BBS, blog and other means timely communication with the educated, exchange ideas, understand and master students' learning, living, interpersonal and other conditions, to promote better exchange of teachers and students, to the soul communication, teaching and learning of good results, so that more targeted ideological and political education. Educators through the collection, collation, analysis of these Internet postings, timely feedback problems and other educational information and education and management, and the establishment of early warning mechanism, as much as possible to solve the problem in the bud, so as to effectively carry out the ideological and political education, improve the timeliness and relevance of ideological and political education.

Network culture to speed up the emergence of this new thing socialization process and promotes socialization of ideological and political education, but also for socialization of ideological and political education has injected new content. Widespread network culture for college students into the community to provide the conditions, it broke through the boundaries of space and time in the past ideological and political education, removal of the universities and society a Road "wall", the university students bring to a wider world .

A network culture is the ideological and political education into a new force. Internet culture fast, open mode of transmission for the ideological and political education workers to provide a large number of innovative educational ideas, fresh educational content and professional means of education, ideological and political education can do large-capacity, large diameter to information output, spread fast, easy operation, greatly enhancing the effectiveness of ideological and political work.

\section{The Challenges of Internet Culture on Ideological and Political Education}

Open and shared characteristics manifested in the form of network culture of college students in the way of thinking, way of life and communication methods have had some impact, but also the "face" of the traditional ideological and political education is facing greater challenges. Interactive way to promote cultural transmission network of ideological and political education must move towards a broader space, in the past by the report, reporting learning, a meeting, talking and so closed, fixed network education cannot meet the requirements of the times, the timeliness of education and durability have been questioned. How to deal with the impact of Internet culture, change the traditional way of education and educational means, ways and means to modernize education, is the current ideological and political education of college students must continue to solve problems.

In the diverse network of cultural environment, university

Health is both a recipient of information, but also the publisher of information. Open, interactive, anonymous network culture makes college students a way to get information more diversified, more open vision, change the past, the process of education in the passive acceptance of the status. In online education as a student and the student's authoritative identity while being digested, the educated and the educators can communicate equally, at the same time, anonymous network culture environment also makes the object of ideological and political education more broadly, the ideological and political education environment more complex, controllable reduced, thus bringing the ideological and political complexity of the educational process.

As the management of the Internet there are loopholes, so the Internet is full of a lot of false information, and even yellow, decadent, reactionary information, the Internet's openness and openness also so that students can easily receive many of their ideas and the adverse physical and mental health spam. Those values which have not yet mature, not very well distinguish right from wrong college misleading, so when they do things over the pursuit of practical, utilitarian, the material interests first, respect for money and pleasure, productivity the money first, self-centered values and ideology, and thus lead to a distortion of their outlook on life, world outlook and values occur. 


\section{The Ways to Improve College Students' Ideological and Political Education under Network Culture}

Focus on network control and guide public opinion in the network cultural environment, college Internet speech, opinion, to express emotions, has become an important part of their lives. Especially since network formation of a certain cultural transmission network public opinion, public expression of these network media often have a certain influence, with a certain tendency, if not handled properly it is likely to be the ideological ideas, values adversely affect the concept and behavior and so on.

With the rapid development of Internet culture, people enjoy a rich cultural achievements of the network, but also encountered some unavoidable moral issues. Such as: network "spoof" expose another's privacy, peep others mailboxes, others virtual property theft, hackers, phishing and other network problems that order to the network and network ethics heavy blow, not only destroyed the network culture a healthy environment is not conducive to the further spread and development of Internet culture. Therefore, we must strengthen the cultural environment of the network under the network of moral education, and as an important part of the ideological and political education so that they become a network of cultural pioneer era civilization.

Laws and regulations reflects the will of the state, in this sense it can effectively ensure the smooth development of ideological and political education to provide the most solid and reliable legal guarantee for education further expanded. However, the advent of computer networks so that information activities go beyond the limitations of traditional educational environment, in virtual, open network environment regulatory network behavior more difficult to control, leading to cyber crime continue to emerge, in this case, relying solely on ethics The power is not enough to be bound, but also to control and maintain law and the traditional legal system has been completely unable to meet the development needs of the information age. Therefore, we must speed up the network of legislation, the establishment of a comprehensive, effective, well-structured legal system.

\section{Conclusion}

Internet culture is at an unprecedented breadth and depth of study of college students, life engaged in multi-dimensional penetration, affect their pursuit of value, morality and behavior, so that their growth and development had a significant impact, but also the ideological and political education problem after another, must be resolved. Under the new situation, study the new characteristics and cultural conditions under network ideological and political education, new issues, promote college students to correctly view and use the network to improve the effectiveness of ideological and political education has become an inevitable choice for the ideological and political educators.

\section{References}

[1] X.G.Liu. The network evaluation methodology of ideological education, J. Ideological and Political Education. 44 (2010) 146-147.

[2] W.P.Guo. Development and the law since the founding of the university students, J. Contemporary Youth Research.18(2005) 55-57.

[3] T.P.Lu. Chinese outstanding cultural about self-confidence and moral education, J. Contemporary Youth Research, 32(2012) 189-190.

[4] P.Wang. Political and ideological education in network culture, J. Times Education (Education Edition), 9(2013) 142-150. 